\title{
Biodegradation of Doxylamine From Wastewater by a Green Microalga, Scenedesmus obliquus
}

\author{
Jiu-Qiang Xiong, Pengfei Cui* and Shaoguo Ru* \\ College of Marine Life Sciences, Ocean University of China, Qingdao, China
}

Pharmaceutical contaminants (PCs) have been recognized as emerging contaminants causing unexpected consequences to environment and humans. There is an urgent need for development of efficient technologies to treat these PCs from water. The current study has investigated the removal capacity of a green microalgal species, Scenedesmus obliquus, for doxylamine, chemical oxygen demand (COD), and nutrients from real wastewater. Results have indicated that $S$. obliquus can grow well in the doxylaminepolluted wastewater with the achievement of $56,78.5,100$, and $89 \%$ removal of doxylamine, COD, total nitrogen (TN), and total phosphorus (TP). Addition of $2 \mathrm{~g} \mathrm{~L}^{-1}$ bicarbonate enhanced the removal of doxylamine up to 63\% and slightly inhibited the removal of COD. Decreased carbohydrate (28-26\%) and increased protein content (30-33\%) of the harvested biomass have been observed after cultivation in the wastewater. The current study has shown the feasibility of using microalgae-based biotechnologies for PC-contaminated wastewater.

Northwestern Polytechnical

University, China

Hu Zhenhu,

Hefei University of Technology, China

Keywords: pharmaceutical contaminants, microalgae, doxylamine, wastewater, bioremediation, biodegradation

Pengfei Cui

cuipengfei@ouc.edu.cn

Shaoguo Ru

rusg@ouc.edu.cn

Specialty section:

This article was submitted to

Microbiotechnology,

a section of the journal

Frontiers in Microbiology

Received: 16 July 2020 Accepted: 22 September 2020 Published: 03 November 2020

Citation:

Xiong J-Q, Cui P and Ru S (2020) Biodegradation of Doxylamine From Wastewater by a Green Microalga, Scenedesmus obliquus.

Front. Microbiol. 11:584020. doi: 10.3389/fmicb.2020.584020

\section{INTRODUCTION}

Pharmaceuticals have been extensively used in human, and culturing of livestock, poultry, and fish to help and facilitate their lives. These high-biologically activated compounds cannot be efficiently degraded, and $>70 \%$ of the uptaken drugs can be excreted into environment with urine and feces (Tran et al., 2018). Numerous countries including United States, China, Canada, Europeans, South Korea, and Japan have found their frequent occurrence in surface water, groundwater, wastewater, seawater, and soil with levels of $\mathrm{ng} \mathrm{L}^{-1}$ to $\mu \mathrm{g} \mathrm{L}^{-1}$ (Patel et al., 2019). These pharmaceutical contaminants (PCs) have been recognized as emerging contaminants since increasing evidences have demonstrated their unexpected consequences on ecological systems and health of humans. For example, PCs at environmental concentrations extended the lag phase of benthic microorganisms, inhibited bacterial denitrification, and reduced microbial diversity (Underwood et al., 2011). Potential permanent damage and consequent effects on coming generations can be induced by PCs demonstrated by their significant influence on uterus [Commission European (CE), 2016]. Existence of the PCs in environment also can generate drug-tolerant bacteria and antibiotic-resistant genes, which can be biomagnificated through food web and finally reach higher consumers (Martínez, 2008). There is an urgent need for effective treatment of such PCs from environments. 
Traditional conventional technologies for wastewater treatment are highly effective for removal of chemical oxygen demand (COD); however, it shows limited performance to remove persistent PCs, total nitrogen (TN) and total phosphorus (TP; Matamoros et al., 2015). Different strategies such as advanced oxidation processes (AOPs), adsorption, bacterial degradation, and electrolysis have shown highly efficient performance of PC treatment (Patel et al., 2019). There are unexpected disadvantages with use of these advanced approaches. For example, more hazardous intermediates can be formed during AOPs and electrolysis (Yang et al., 2019); organic matrixes of the wastewater can significantly decrease the adsorption capacity (Ersan et al., 2017); and drug-resistant bacteria can be easily acclimated during degradation of PCs (Xiong et al., 2018). Microalgae-based biotechnologies have shown potential applications for advanced treatment of different wastewaters such as municipal wastewater, swine wastewater, poultry litter anaerobic digestate, industrial wastewater, and aquaculture wastewater (Yu et al., 2015; Zhuang et al., 2020). Additionally, microalgae can utilize the nutrients and carbon sources of wastewaters for their cellular metabolisms with generating biomass for production of bioenergy and high value-added compounds (Perez-Garcia et al., 2011; Fernandes et al., 2017). Microalgal treatment of PCs needs further exploration to achieve potential application under current scenario; in particular, more attention should be paid on the development in the performance for removal of nutrients and PCs from real wastewaters.

In this study, the microalgal degradation of a frequently found PC, doxylamine from real wastewater, has been investigated. Doxylamine has been frequently detected in different water sources with concentrations of ng $\mathrm{L}^{-1}$ to $\mu \mathrm{g} \mathrm{L}^{-1}$. Earlier studies mainly investigated the formation dynamics of N-nitrosodimethylamine (NDMA) from doxylamine since NDMA is a highly carcinogenic product and can be easily formed during oxidation of amine-based PCs (Shen and Andrews, 2011). Rare investigations have focused on microalgal removal of doxylamine from real wastewater. Therefore, the current study aims to investigate the removal efficiencies of doxylamine by microalgae from municipal wastewater, the effect of doxylamine on the growth of microalgae, and the effect of doxylamine on the microalgal performance for treatment of COD, TN, and TP.

\section{MATERIALS AND METHODS}

\section{Chemicals}

Doxylamine succinate salt with a molecular weight $338.46 \mathrm{~g} \mathrm{~mol}^{-1}$ has been obtained from Sigma-Aldrich (St. Louis, USA). Compositions of mobile phase were acetonitrile, water, and formic acid, which are at HPLC-grade and were purchased from Thermo Fisher Scientific and Mallinckrodt Baker Inc. (USA).

\section{Removal of Doxylamine by Scenedesmus obliquus From Real Wastewater}

The removal capability of a widely distributed freshwater microalgal species, $S$. obliquus, for doxylamine from real wastewater has been investigated. The microalgal inoculum has been cultivated in Erlenmeyer flasks containing sterilized Bold's Basal Medium (BBM, $150 \mathrm{ml}$ ) under a continuous light source with an intensity of 45-50 $\mu \mathrm{mol}$ photons $\mathrm{m}^{-2} \mathrm{~s}^{-1}$ for 7 days in a shaking incubator $(150 \mathrm{rpm})$. The temperature was $27^{\circ} \mathrm{C}$. The microalgal cells were harvested by centrifugation $(4,000 \mathrm{rpm})$, and the biomass was washed three times with distilled water before its further use.

Batch experiments to investigate the removal of doxylamine ( $1 \mathrm{mg} \mathrm{L}^{-1}$ ) from real wastewater by S. obliquus were conducted in 250-ml Erlenmeyer flasks containing $150 \mathrm{ml}$ of raw wastewater inoculated with $1.5 \%$ of microalgal suspension with an optical density at $680 \mathrm{~nm}\left(\mathrm{OD}_{680}\right)$ of 1.0. The reduction of doxylamine in wastewater was examined by supplying the culture flasks with the same amount of doxylamine without inoculum of microalgae. The effect of sodium bicarbonate $\left(\mathrm{NaHCO}_{3}, 2 \mathrm{~g} \mathrm{~L}^{-1}\right)$ was also investigated since biocarbonate has been found to be an enhancement strategy not only for microalgal growth but also for promoting the nutritional treatment efficiency (Pancha et al., 2015; Zhai et al., 2020). On the other aspect, high cost of carbon dioxide $\left(\mathrm{CO}_{2}\right)$ capture and transportation and $\mathrm{CO}_{2}$ loss for microalgal cultivation have enabled people for searching alternative solutions to $\mathrm{CO}_{2}$ fixation (Chi et al., 2011). The bicarbonate-carbon cycling system has been proposed as an advanced approach (Song et al., 2019). All the experiments were conducted in triplicate.

\section{Determination of Microalgal Growth and Biochemical Characteristics}

Growth of S. obliquus was determined according to the changes of the microalgal culture at $\mathrm{OD}_{680}$ (Xiong et al., 2020). In a brief, the cell numbers of the microalgal cultures with different absorbance were counted using a Countess II Automated Cell Counter (Thermo Fisher Scientific, USA). A linear relationship between microalgal cell numbers and $\mathrm{OD}_{680}$ has been found as follows:

Cell numbers of S.obliquus $\left(10^{7} \mathrm{ml}^{-1}\right)=1.3914 \times \mathrm{OD}_{680}+$

$0.0038\left(R^{2}=0.999\right)$

The specific growth rate $(\mu)$ was calculated using the following equation:

$$
\boldsymbol{\mu}=\frac{\ln N_{2}-\ln N_{0}}{t_{2}-t_{0}}
$$

where $N_{2}$ is the dry cell weight at time $t_{2}$ and $N_{0}$ is the dry cell weight at time $t_{0}$ (day 0 ).

Total chlorophyll and carotenoid content of S. obliquus were measured according to an earlier reported protocol (Kurade et al., 2016). Carbohydrate of microalgal biomass was analyzed using phenol-sulfuric acid method with glucose as a standard, and amount of the protein was measured using Bradford assay (Xiong et al., 2019).

\section{Analytical Measurement of Doxylamine, COD, and Nutrients}

Samples for analysis of doxylamine have been taken at regular intervals of $0,2,4,6,8$ and 10 days, which were firstly centrifuged 
and then filtered using $0.45-\mu \mathrm{m}$ membrane filters (Pall Life Sciences, USA). Twenty-microliter solution has been injected into a high-performance liquid chromatography (HPLC) equipped with a UV-visible detector (Waters 2695, USA). The running mobile phase consisted of acetonitrile, water, and formic acid at a ratio of 10:90:0.1 (v/v/v), and the flow rate was $0.8 \mathrm{ml} \mathrm{min}^{-1}$.

Kinetics analyses of doxylamine removal have been conducted using zero-order model, first-order model, and second-order model based on the following equations:

$$
\begin{aligned}
C_{t} & =-k t+C_{0} \\
\ln C_{t} & =-k t+\ln C_{0} \\
\frac{1}{C_{t}} & =k t+\frac{1}{C_{0}}
\end{aligned}
$$

where $C_{0}$ is the initial amount of doxylamine, $C_{\mathrm{t}}$ is the residual concentration at time $t, k$ is the removal rate constant $\left(\right.$ day $\left.^{-1}\right)$, and $t$ refers to the sampling time. Equation (3) presents zeroorder kinetic reaction; Eq. (4) is for first-order kinetic reaction; and Eq. (5) is for calculation of second-order kinetic reaction parameters.

COD of wastewater was determined with a reference to the guideline of APHA 5220D, which uses potassium hydrogen phthalate for standard curve. TN and TP were measured using the kits named Test $\mathrm{N}$ Tube Total Nitrogen Reagent Set $\left(2-150 \mathrm{mg} \mathrm{L}^{-1}\right)$ and the phosphorus (total) TNT Reagent Set (0.06-3.5 $\left.\mathrm{mg} \mathrm{L} \mathrm{L}^{-1}\right)$. All the kits were purchased from Hach (USA), and the analysis was done according to the manufacturer's protocol. $\mathrm{pH}$ of the samples was determined using an Orion Star A321 pH portable meter (Thermo Fisher Scientific, USA).

\section{RESULTS AND DISCUSSION}

\section{Growth Pattern of Scenedesmus obliquus}

The growth rate of $S$. obliquus with and without doxylamine in wastewater is shown in Figure 1. The density of microalgal cells have been calculated from Eq. (1), and were $20.67 \times 10^{6} \mathrm{ml}^{-1}$, $20.51 \times 10^{6} \mathrm{ml}^{-1}$, and $17.65 \times 10^{6} \mathrm{ml}^{-1}$ for WA (wastewater with inoculum of microalgae), WAD (wastewater with addition of microalgae and doxylamine), and $\mathrm{WADH}$ (wastewater with addition of microalgae, doxylamine, and bicarbonate), respectively (Figure 1A). The results indicated that the exposed amount of doxylamine in wastewater negligibly influenced the growth of S. obliquus. Specific growth rate (SGR) of S. obliquus in different experimental conditions was calculated form Eq. (2), and have been shown in Figure 1B. There was no observable difference of SGR with the effect of either doxylamine or the combination of doxylamine and bicarbonate during 10 days of cultivation. The negligible difference of microalgal growth and SGR influenced by doxylamine indicated that $S$. obliquus is a tolerant species toward the treatment of doxylamine-polluted wastewater. Earlier studies also demonstrated low concentrations of levofloxacin, amoxicillin, and ciprofloxacin (Xiong et al., 2017; Xie et al., 2020). For example, the growth of a green microalga, Chlorella vulgaris, was not influenced with exposure up to $5 \mathrm{mg} \mathrm{L}^{-1}$
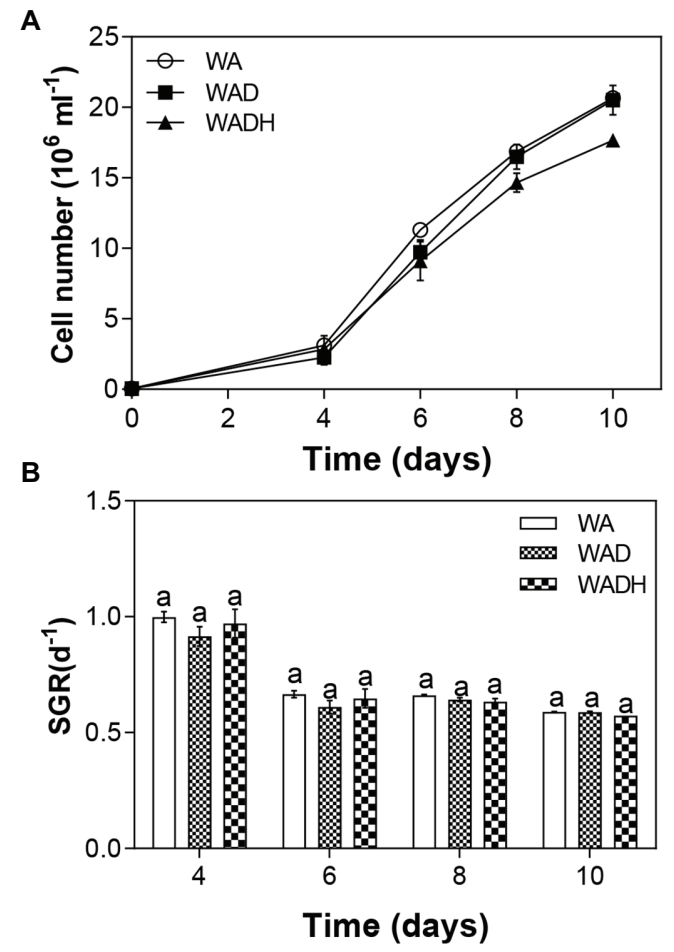

FIGURE 1 | Cell numbers (A) and specific growth rate (B) of Scenedesmus obliquus in wastewater (WA), wastewater with doxylamine (WAD), and wastewater with addition of doxylamine and biocarbonate (WADH) during 10 days of cultivation.

levofloxacin (Xiong et al., 2017). Xie et al. (2020) investigate the effect of ciprofloxacin on a Chlamydomonas sp., which showed that there was no significant alteration of microalgal growth under $10 \mathrm{mg} \mathrm{L}^{-1}$ ciprofloxacin. Liu et al. (2016) demonstrated that there was a hermetic effect of amoxicillin on the growth of a cyanobacteria, Microcystis aeruginosa. All these results indicated the engineering feasibility of microalgae in different conditions. However, there are many studies showing the inhibitory effect of various PCs on microalgal growth. For example, Li et al. (2020) found that the growth of Chlorella pyrenoidosa was significantly inhibited by roxithromycin from $0.25 \mathrm{mg} \mathrm{L}^{-1}$ to $2 \mathrm{mg} \mathrm{L}^{-1}$ (Li et al., 2020). A mixture of sulfamethazine and sulfamethoxazole significantly inhibited the growth of S. obliquus at concentrations from $0.05 \mathrm{mg} \mathrm{L}^{-1}$ to $0.5 \mathrm{mg} \mathrm{L}^{-1}$ (Xiong et al., 2019). Transcriptomic analysis of the microalgal cells exposed to high concentrations of PCs indicated that PCs downregulated the expressions of genes involved in DNA replication and repair process, biosynthesis of biochemicals (steroids, sesquiterpenoid, fatty acids, triterpenoid), and photosynthesis, thus causing toxicity to microalgal cells (Wei et al., 2019; Guo et al., 2020).

\section{Changes of Microalgal Pigments Influenced by Doxylamine}

Photosynthesis of microalgae mediated by chlorophyll and carotenoid plays essential roles to convert light energy, carbon 
dioxide, and water into microalgal biomass. Thus, evaluation of pigment production helps to understand the overall cellular metabolic activities (Blossom et al., 2019; Stock et al., 2020). As shown in Figure 2, total chlorophyll of S. obliquus was $27.21,26.68$, and $16.81 \mathrm{mg} \mathrm{g}^{-1}$ in wastewater, doxylamine polluted wastewater, and wastewater with doxylamine and sodium biocarbonate, respectively, whereas the amount of carotenoid showed a similar trend with a final production of $5.62,5.15$, and $3.35 \mathrm{mg} \mathrm{g}^{-1}$. The result agreed with the microalgal growth pattern, which indicated that there was no significant effect of doxylamine $\left(1 \mathrm{mg} \mathrm{L}^{-1}\right)$ on the microalgal photosynthesis. The decreased content of microalgal chlorophyll is consistent with earlier studies. For example, phytoplankton photosystem II (PSII) efficiency $(F v / F m)$ of a marine microalga, Nannochloropsis salina, was slightly inhibited with the addition of $2 \mathrm{~g} \mathrm{~L}^{-1}$ bicarbonate (White et al., 2013). Fv/Fm of a marine green microalga Tetraselmis subcordiformis was significantly inhibited with $5 \mathrm{~g} \mathrm{~L}^{-1}$ bicarbonate (Qi et al., 2019). Sampathkumar and Gothandam (2019) demonstrated that chlorophyll and carotenoid content of a green microalga, C. vulgaris, increased at low concentration of bicarbonate $(0-150 \mathrm{mM})$ and decreased at $200 \mathrm{mM}$ bicarbonate (Sampathkumar and Gothandam, 2019). High concentrations of bicarbonate induced adverse effects on photosynthetic pigments, which can be due to energy interactions for photosynthetic carbon dioxide fixation and energy-consuming metabolic pathways since assimilation of bicarbonate involves an active transport (Srinivasan et al., 2018; Qi et al., 2019).

\section{Removal of Doxylamine by Scenedesmus obliquus From Real Wastewater}

Figure 3 showed the removal of doxylamine from real wastewater by $S$. obliquus. There was $15 \%$ decrease of the exposed doxylamine concentrations in the wastewater without inoculum of microalgae, while growth of $S$. obliquus removed 56\% doxylamine $\left(1 \mathrm{mg} \mathrm{L}^{-1}\right)$ after 10 days of cultivation, and addition of sodium bicarbonate increased the removal up to $63 \%$. Removal kinetics of doxylamine

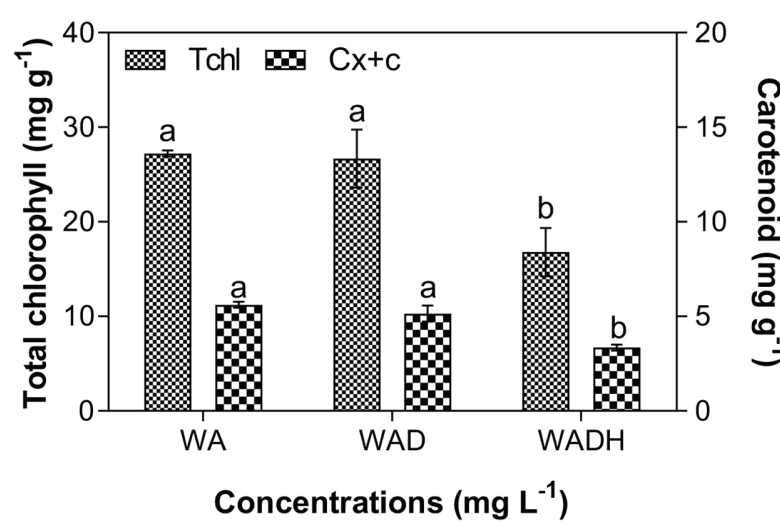

FIGURE 2 | Total chlorophyll and carotenoid content of Scenedesmus obliquus after cultivation in wastewater (WA), wastewater with doxylamine (WAD), and wastewater with addition of doxylamine and biocarbonate (WADH). removal at different experimental conditions were analyzed using zero-order, first-order, and second-order reaction models (Table 1). The removal kinetic constant $\left(k\right.$, day $\left.^{-1}\right)$ of doxylamine from wastewater was $0.057,0.064$ and 0.014 day $^{-1}$ for wastewater with microalgae, wastewater without microalgae and bicarbonate, and wastewater without microalgae, respectively, and half-lives ( $T_{1 / 2}$, day) increased from 8.31 days to 36.3 days, which were calculated by zero-order kinetic reaction $\left(r^{2}=0.87-0.99\right)$. Firstorder kinetic analysis showed the removal kinetic constant $\left(k\right.$, day $\left.^{-1}\right)$ of doxylamine were $0.12,0.16$, and 0.02 day $^{-1}$ with half-lives $\left(T_{1 / 2}\right.$, day) of 5.56, 4.33, and $34.15\left(r^{2}=0.86-0.99\right)$. Second-order kinetic reaction constant $\left(k\right.$, day $\left.{ }^{-1}\right)$ was 0.1224 , 0.1675 , and 0.0166 with half-lives $\left(T_{1 / 2}\right.$, day) of $10.26,8.34$, and $59.79\left(r^{2}=0.94-0.95\right)$ for WAD, WADH, and $\mathrm{WD}$, respectively. Removal of doxylamine using microalgae from

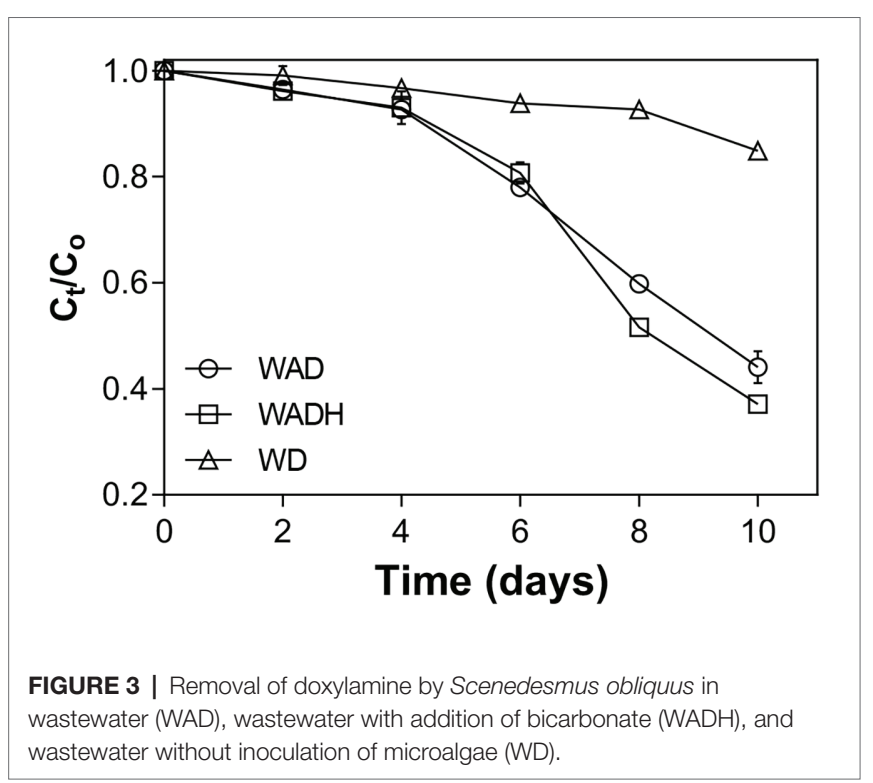

TABLE 1 | Kinetic parameters of doxylamine $\left(1 \mathrm{mg} \mathrm{L}^{-1}\right)$ degradation by Scenedesmus obliquus in different experimental conditions.

\begin{tabular}{|c|c|c|c|}
\hline \multirow{2}{*}{ Experiments } & \multicolumn{3}{|c|}{ Zero-order kinetic reaction } \\
\hline & $k\left(\right.$ day $\left.^{-1}\right)$ & $T_{1 / 2}$ (day) & $r^{2}$ \\
\hline WAD & 0.057 & 9.30 & 0.99 \\
\hline WADH & 0.064 & 8.31 & 0.97 \\
\hline WD & 0.014 & 36.30 & 0.87 \\
\hline \multirow{2}{*}{ Experiments } & \multicolumn{3}{|c|}{ First-order kinetic reaction } \\
\hline & $k\left(\right.$ day $\left.^{-1}\right)$ & $T_{1 / 2}$ (day) & $r^{2}$ \\
\hline WAD & 0.1247 & 5.56 & 0.99 \\
\hline WADH & 0.1601 & 4.33 & 0.97 \\
\hline WD & 0.020 & 34.15 & 0.86 \\
\hline \multirow{2}{*}{ Experiments } & \multicolumn{3}{|c|}{ Second-order kinetic reaction } \\
\hline & $k\left(\right.$ day $\left.^{-1}\right)$ & $T_{1 / 2}$ (day) & $r^{2}$ \\
\hline WAD & 0.1224 & 10.26 & 0.95 \\
\hline WADH & 0.1675 & 8.34 & 0.94 \\
\hline WD & 0.0166 & 59.79 & 0.94 \\
\hline
\end{tabular}

$k$, kinetic removal rate constant (day-1); $T_{1 / 2}$, removal half-life (day); $r^{2}$, correlation coefficient; WAD, wastewater with doxylamine and microalgae; WADH, wastewater with doxylamine, microalgae, and biocarbonate; WD, wastewater with doxylamine. 
real wastewater has been rarely reported. However, numerous studies have demonstrated the removal capacity of microalgae for various PCs. Microalgae-based biotechnologies have been proven as a promising tool toward effective treatment of diverse organic and inorganic pollutants (Villar-Navarro et al., 2018; Sutherland and Ralph, 2019). For example, Vo et al. (2020) found that Chlorella sp., can remove $16-58 \%$ of tetracycline, sulfamethoxazole, and bisphenol A, and the removal efficiency was enhanced up to $99 \%$ with a cometabolic mechanism (Vo et al., 2020). It has demonstrated that the high-rate algal ponds (HRAPs) removed 22-90\% of 26 PCs including acetaminophen, ibuprofen, and oxybenzone from urban wastewater (Matamoros et al., 2015). Instead of upflow anaerobic sludge blanket in the wastewater treatment plant, high-rate algae ponds have been used as a tertiary treatment for nutrients and other contaminants from wastewater, which showed 15 and $50 \%$ higher removal of diclofenac and some specific antibiotics and diuretics (Villar-Navarro et al., 2018).

\section{Removal of COD and Nutrients by Scenedesmus obliquus}

Figure 4 showed the changes of $\mathrm{pH}$, and removal of $\mathrm{COD}$, $\mathrm{TN}$, and $\mathrm{TP}$ in different experimental sets. Investigation of the microalgal capacity for elimination of various contaminants is essential since it can help to screen a robust species. The $\mathrm{pH}$ of the raw wastewater (WD) increased from 6.4 to 8.70 after 10 days of cultivation, and $\mathrm{pH}$ of wastewaters with cultivation of microalgae (WA), doxylamine (WAD), and/or bicarbonate (WADH) increased up to 10.85 (Figure 4A). Growth of microalgae can increase $\mathrm{pH}$ as uptake of inorganic carbon (e.g., $\mathrm{HCO}_{3}{ }^{-}$) in photosynthesis induces release of hydroxyl ions. Nitrate reduction also causes an increase in $\mathrm{pH}$ since denitrification process will consume hydrogen ions. Concentrations of COD decreased from $235.67 \mathrm{mg} \mathrm{L^{-1 }}$ to $45.67,47.33,50.67$, and $57.33 \mathrm{mg} \mathrm{L}^{-1}$ for $\mathrm{WD}$, WA, WAD, and WADH, respectively. Initial amount of $\mathrm{TN}$ was $33.5 \mathrm{mg} \mathrm{L}^{-1}$, which achieved 23.9, 94,100 , and $98.5 \%$ removal in WD, WA, WAD, and WADH. In case of $\mathrm{TP}$, it was observed that the doses declined from $6.67 \mathrm{mg} \mathrm{L}^{-1}$ to $5.72,1.10,0.75$, and $1.05 \mathrm{mg} \mathrm{L}^{-1}$, which equaled to $14.2,83.5,88.8$, and $84.3 \%$ removal, respectively. Microalgae are able to assimilate different nitrogen sources (ammonium, nitrate, and nitrite) from wastewater using different enzymes such as glutamate synthase, glutamine synthetase, glutamate dehydrogenase, nitrite reductase, and nitrate reductase (PerezGarcia et al., 2011). A microalgal species, Chlorella sp., decreased the TN and TP of municipal wastewater from 19.1 to $1.5 \mathrm{mg} \mathrm{L}^{-1}$ and from 3 to $0.2 \mathrm{mg} \mathrm{L}^{-1}$, respectively, after 9 days of cultivation (Cho et al., 2011; Ji et al., 2013). On the other hand, the presence of other environmental factors such as PCs and heavy metals in wastewaters has significant effect on the removal efficiency of TN and TP. For example, concentrations of $150 \mu \mathrm{M}$ $\mathrm{Cd}^{2+}$, $\mathrm{Cu}^{2+}$, or $\mathrm{Zn}^{2+}$ inhibited $75 \%$ removal of nitrate in Chlamydomonas mexicana due to the downregulated activity of glutamine synthetase (Devriese et al., 2001). In the current study, there was no observable effect of doxylamine on the removal efficiency of COD, TN, and TP, indicating the feasibility of $S$. obliquus toward an advanced treatment of wastewater.

\section{Carbohydrate and Protein Content of Scenedesmus obliquus Cultivated in Wastewater}

Advantages of microalgae-based wastewater treatment technologies include the high value-added by-products such as carbohydrate and protein-rich microalgal biomass. The effect

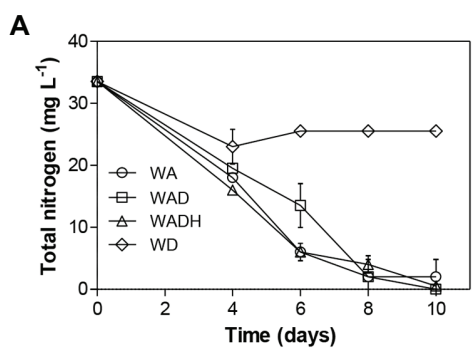

C

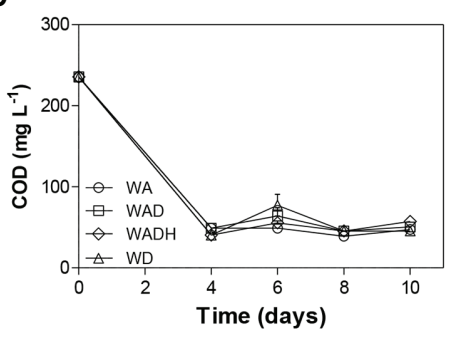

B

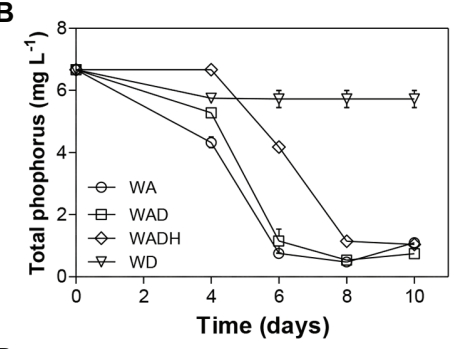

D

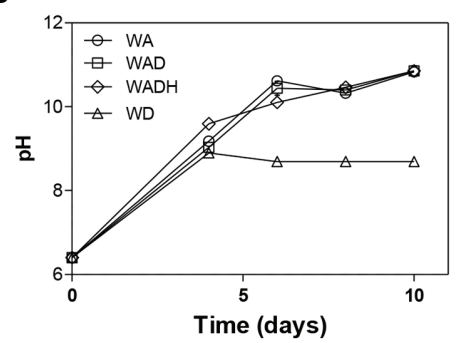

FIGURE 4 | Removal of (A) total nitrogen (TN), (B) total phosphorus (TP), (C) chemical oxygen demand (COD), and (D) change of pH in wastewater without microalgae (WD), wastewater with microalgae (WA), wastewater with microalgae and doxylamine (WAD), and wastewater with microalgae, doxylamine, and bicarbonate (WADH). 


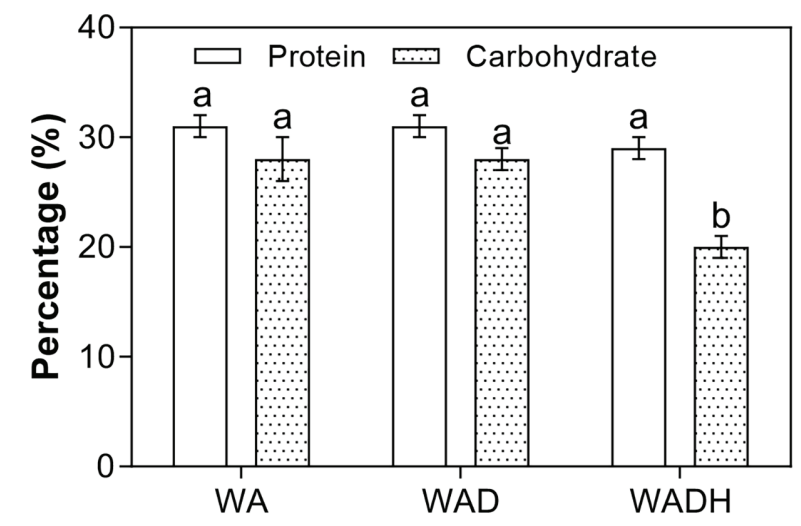

FIGURE 5 | Carbohydrate and protein content of Scenedesmus obliquus after cultivation in wastewater (WA), wastewater with doxylamine (WAD), and wastewater with addition of doxylamine and biocarbonate (WADH).

of doxylamine and bicarbonate on the carbohydrate and protein compositions of the harvested biomass of S. obliquus is shown in Figure 5. There were 27, 28, and 26\% carbohydrate, and 30,31 , and $33 \%$ protein in the microalgal biomass cultivated in WA, WAD, and WADH, respectively, after 10 days of cultivation. Carbohydrate, protein, and lipid are the three main components of microalgal biomass, and changes of their contents can indicate the overall metabolic activities induced by different environments. Earlier studies demonstrated that the PCs such as sulfamethazine and sulfamethoxazole decreased the carbohydrate content of S. obliquus since the pollutants disrupted the photosynthesis for carbon fixation and conversion for formation of starch and lignin (Xiong et al., 2019). There was a slight increase in the protein percentage, which is consistent with other studies (Sampathkumar and Gothandam, 2019; Li et al., 2020). Elevated protein content can be caused by the increased synthesis of metabolic and protective enzymes such as degradation and antioxidant enzymes to help in detoxification.

\section{REFERENCES}

Blossom, H. E., Markussen, B., Daugbjerg, N., Krock, B., Norlin, A., and Hansen, P. J. (2019). The cost of toxicity in microalgae: direct evidence from the dinoflagellate Alexandrium. Front. Microbiol. 10:1056. doi: 10.3389/ fmicb.2019.01065

Chi, Z., O'Fallon, J. V., and Chen, S. (2011). Bicarbonate produced from carbon capture for algae culture. Trends Biotechnol. 29, 537-541. doi: 10.1016/j. tibtech.2011.06.006

Cho, S., Luong, T. T., Lee, D., Oh, U. K., and Lee, T. (2011). Reuse of effluent water from a municipal wastewater treatment plant in microalgae cultivation for biofuel production. Bioresour. Technol. 102, 8639-8645. doi: 10.1016/j. biortech.2011.03.037

Commission European (CE) (2016). Communication from the Commission to the European Parliament, the Council, the European Economic and Social Committee and the Committee of the Regions. A European Agenda for the Collaborative Economy (2016).

Devriese, M., Tsakaloudi, V., Garbayo, I., León, R., Vílchez, C., and Vigara, J. (2001). Effect of heavy metals on nitrate assimilation in the eukaryotic microalga Chlamydomonas reinhardtii. Plant Physiol. Biochem. 39, 443-448. doi: 10.1016/S0981-9428(01)01257-8

\section{CONCLUSION}

The treatment capacity of a green microalga, S. obliquus, for doxylamine-contaminated wastewater was investigated in this study, and the results showed that $S$. obliquus can grow well under current experimental conditions. There was negligible effect of doxylamine on S. obliquus and its biochemical characteristics including chlorophyll, carotenoid, and carbohydrate. In contrast, doxylamine slightly increased the protein content. S. obliquus showed high removal capacity toward doxylamine, COD, TN, and TP, indicating its feasibility for the remediation of doxylaminepolluted wastewater. Further studies should be conducted in pilot-scale plants to investigate the engineering application of microalgae-based biotechnology.

\section{DATA AVAILABILITY STATEMENT}

All datasets presented in this study are included in the article/ supplementary material.

\section{AUTHOR CONTRIBUTIONS}

J-QX: conceptualization, funding acquisition, resources, methodology, validation, formal analysis, investigation, visualization, writing - original draft, and writing - review and editing. PC: writing - review and editing. SR: funding acquisition, resources, and writing - review and editing. All authors contributed to the article and approved the submitted version.

\section{FUNDING}

This work was supported by the National Key Research and Development Program of China (2019YFC1605704), and startup funds provided by Ocean University of China for highly talented young researchers (862001013135).
Ersan, G., Apul, O. G., Perreault, F., and Karanfil, T. (2017). Adsorption of organic contaminants by graphene nanosheets: a review. Water Res. 126, 385-398. doi: 10.1016/j.watres.2017.08.010

Fernandes, T., Suárez-Muñoz, M., Trebuch, L. M., Verbraak, P. J., and de Waal, D. B. V. (2017). Toward an ecologically optimized N:P recovery from wastewater by microalgae. Front. Microbiol. 8:1742. doi: 10.3389/ fmicb.2017.01742

Guo, J., Bai, Y., Chen, Z., Mo, J., Li, Q., Sun, H., et al. (2020). Transcriptomic analysis suggests the inhibition of DNA damage repair in green alga Raphidocelis subcapitata exposed to roxithromycin. Ecotoxicol. Environ. Saf. 201:110737. doi: 10.1016/j.ecoenv.2020.110737

Ji, M. K., Abou-Shanab, R. A. I., Kim, S. H., Salama, E. S., Lee, S. H., Kabra, A. N., et al. (2013). Cultivation of microalgae species in tertiary municipal wastewater supplemented with $\mathrm{CO}_{2}$ for nutrient removal and biomass production. Ecol. Eng. 58, 142-148. doi: 10.1016/j.ecoleng.2013.06.020

Kurade, M. B., Kim, J. R., Govindwar, S. P., and Jeon, B. H. (2016). Insights into microalgae mediated biodegradation of diazinon by Chlorella vulgaris: microalgal tolerance to xenobiotic pollutants and metabolism. Algal Res. 20, 126-134. doi: 10.1016/j.algal.2016.10.003

Li, J., Min, Z., Li, W., Xu, L., Han, J., and Li, P. (2020). Interactive effects of roxithromycin and freshwater microalgae, Chlorella pyrenoidosa: toxicity and 
removal mechanism. Ecotoxicol. Environ. Saf. 191:110156. doi: 10.1016/j. ecoenv.2019.110156

Liu, Y., Chen, S., Zhang, J., and Gao, B. (2016). Growth, microcystin-production and proteomic responses of Microcystis aeruginosa under long-term exposure to amoxicillin. Water Res. 93, 141-152. doi: 10.1016/j.watres.2016.01.060

Martínez, J. L. (2008). Antibiotics and antibiotic resistance genes in natural environments. Science 321, 365-367. doi: 10.1126/science.1159483

Matamoros, V., Gutiérrez, R., Ferrer, I., García, J., and Bayona, J. M. (2015). Capability of microalgae-based wastewater treatment systems to remove emerging organic contaminants: a pilot-scale study. J. Hazard. Mater. 288, 34-42. doi: 10.1016/j.jhazmat.2015.02.002

Pancha, I., Chokshi, K., Ghosh, T., Paliwal, C., Maurya, R., and Mishra, S. (2015). Bicarbonate supplementation enhanced biofuel production potential as well as nutritional stress mitigation in the microalgae Scenedesmus sp. CCNM 1077. Bioresour. Technol. 193, 315-323. doi: 10.1016/j. biortech.2015.06.107

Patel, M., Kumar, R., Kishor, K., Misna, T., Pittman, C. U., and Mohan, D. (2019). Pharmaceuticals of emerging concern in aquatic systems: chemistry, occurrence, effects, and removal methods. Chem. Rev. 119, 3510-3673. doi: 10.1021 acs.chemrev.8b00299

Perez-Garcia, O., Escalante, F. M. E., de-Bashan, L. E., and Bashan, Y. (2011). Heterotrophic cultures of microalgae: metabolism and potential products. Water Res. 45, 11-36. doi: 10.1016/j.watres.2010.08.037

Qi, M., Yao, C., Sun, B., Cao, X., Fei, Q., Liang, B., et al. (2019). Application of an in situ $\mathrm{CO}_{2}$-bicarbonate system under nitrogen depletion to improve photosynthetic biomass and starch production and regulate amylose accumulation in a marine green microalga Tetraselmis subcordiformis. Biotechnol. Biofuels 12:184. doi: 10.1186/s13068-019-1523-7

Sampathkumar, S. J., and Gothandam, K. M. (2019). Sodium bicarbonate augmentation enhances lutein biosynthesis in green microalgae Chlorella pyrenoidosa. Biocatal. Agric. Biotechnol. 22:101406. doi: 10.1016/j. bcab.2019.101406

Shen, R., and Andrews, S. A. (2011). NDMA formation kinetics from three pharmaceuticals in four water matrices. Water Res. 45:5687-5694. doi: 10.1016/j.watres.2011.08.034

Song, C., Qiu, Y., Li, S., Liu, Z., Chen, G., Sun, L., et al. (2019). A novel concept of bicarbonate-carbon utilization via an absorption-microalgae hybrid process assisted with nutrient recycling from soybean wastewater. J. Clean. Prod. 237:117864. doi: 10.1016/j.jclepro.2019.117864

Srinivasan, R., Mageswari, A., Subramanian, P., Suganthi, C., Chaitanyakumar, A., Aswini, V., et al. (2018). Bicarbonate supplementation enhances growth and biochemical composition of Dunaliella salina V-101 by reducing oxidative stress induced during macronutrient deficit conditions. Sci. Rep. 8:6972. doi: 10.1038/s41598-018-25417-5

Stock, F., Bilcke, G., Decker, S. D., Osuna-Cruz, C. M., den Berge, K. V., Vancaester, E., et al. (2020). Distinctive growth and transcriptional changes of the diatom Seminavis robusta in response to quorum sensing related compounds. Front. Microbiol. 11:1240. doi: 10.3389/fmicb.2020.01240

Sutherland, D. L., and Ralph, P. J. (2019). Microalgal bioremediation of emerging contaminants - opportunities and challenges. Water Res. 164:114921. doi: 10.1016/j.watres.2019.114921

Tran, N. H., Reinhard, M., and Gin, K. Y. H. (2018). Occurrence and fate of emerging contaminants in municipal wastewater treatment plants from different geographical regions-a review. Water Res. 133, 182-207. doi: 10.1016/j. watres.2017.12.029

Underwood, J. C., Harvey, R. W., Metge, D. W., Repert, D. A., Baumgarter, L. K., Smith, R. L., et al. (2011). Effects of the antimicrobial sulfamethoxazole on groundwater bacterial enrichment. Environ. Sci. Technol. 45, 3096-3101. doi: $10.1021 /$ es103605e
Villar-Navarro, E., Baena-Nogueras, R. M., Paniw, M., Perales, J. A., and Lara-Martín, P. A. (2018). Removal of pharmaceuticals in urban wastewater: high rate algae pond (HRAP) based technologies as an alternative to activated sludge based processes. Water Res. 139, 19-29. doi: 10.1016/j. watres.2018.03.072

Vo, H. N. P., Ngo, H. H., Guo, W., Nguyen, K. H., Chang, S. W., Nguyen, D. D., et al. (2020). Micropollutants cometabolism of microalgae for wastewater remediation: effect of carbon sources to cometabolism and degradation products. Water Res. 183:115974. doi: 10.1016/j.watres.2020.115974

Wei, L., Hajjami, M. E., Shen, C., You, W., Lu, Y., Li, J., et al. (2019). Transcriptomic and proteomic responses to very low $\mathrm{CO}_{2}$ suggest multiple carbon concentrating mechanisms in Nannochloropsis oceanica. Biotechnol. Biofuels 12:168. doi: 10.1186/s13068-019-1506-8

White, D. A., Pagarette, A., Rooks, P., and Ali, S. T. (2013). The effect of sodium bicarbonate supplementation on growth and biochemical composition of marine microalgae cultures. J. Appl. Phycol. 25, 153-165. doi: 10.1007/ s10811-012-9849-6

Xie, P., Chen, C., Zhang, C., Su, G., Ren, N., and Ho, S. H. (2020). Revealing the role of adsorption in ciprofloxacin and sulfadiazine elimination routes in microalgae. Water Res. 172:115475. doi: 10.1016/j.watres.2020.115475

Xiong, J. Q., Govindwar, S. P., Kurade, M. B., Paeng, K. J., Roh, H. S., Khan, M. A., et al. (2019). Toxicity of sulfamethazine and sulfamethoxazole and their removal by a green microalga, Scenedesmus obliquus. Chemosphere 218, 551-558. doi: 10.1016/j.chemosphere.2018.11.146

Xiong, J. Q., Kurade, M. B., and Jeon, B. H. (2017). Biodegradation of levofloxacin by an acclimated freshwater microalga, Chlorella vulgaris. Chem. Eng. J. 313, 1251-1257. doi: 10.1016/j.cej.2016.11.017

Xiong, J. Q., Kurade, M. B., and Jeon, B. H. (2018). Can microalgae remove pharmaceutical contaminants from water? Trends Biotechnol. 36, 30-44. doi: 10.1016/j.tibtech.2017.09.003

Xiong, J. Q., Ru, S., Zhang, Q., Jang, M., Kurade, M. B., Kim, S. H., et al. (2020). Insights into the effect of cerium oxide nanoparticle on microalgal degradation of sulfonamides. Bioresour. Technol. 309:123452. doi: 10.1016/j. biortech.2020.123452

Yang, Q., Ma, Y., Chen, F., Yao, F., Sun, J., Wang, S., et al. (2019). Recent advances in photo-activated sulfate radical-advanced oxidation process (SR-AOP) for refractory organic pollutants removal in water. Chem. Eng. J. 378:122149. doi: 10.1016/j.cej.2019.122149

Yu, X., Chen, L., and Zhang, W. (2015). Chemicals to enhance microalgal growth and accumulation of high-value bioproducts. Front. Microbiol. 6:56. doi: $10.3389 /$ fmicb. 2015.00056

Zhai, X., Zhu, C., Zhang, Y., Pang, H., Kong, F., Wang, J., et al. (2020). Seawater supplemented with bicarbonate for efficient marine microalgae production in floating photobioreactor on ocean: a case study of Chlorella sp. Sci. Total Environ. 738:139439. doi: 10.1016/j.scitotenv.2020.139439

Zhuang, L. L., Li, M., and Ngo, H. H. (2020). Non-suspended microalgae cultivation for wastewater refinery and biomass production. Bioresour. Technol. 308:123320. doi: 10.1016/j.biortech.2020.123320

Conflict of Interest: The authors declare that the research was conducted in the absence of any commercial or financial relationships that could be construed as a potential conflict of interest.

Copyright (๑) 2020 Xiong, Cui and Ru. This is an open-access article distributed under the terms of the Creative Commons Attribution License (CC BY). The use, distribution or reproduction in other forums is permitted, provided the original author(s) and the copyright owner(s) are credited and that the original publication in this journal is cited, in accordance with accepted academic practice. No use, distribution or reproduction is permitted which does not comply with these terms. 